\title{
PENGARUH KEPRIBADIAN, ORIENTASI KERJA, DAN PENEMPATAN TERHADAP KINERJA PEGAWAI
}

\author{
Sri Langgeng Ratnasari ${ }^{1)}$, Mutia Septiani ${ }^{2}$ \\ ${ }^{1}$ Program Pascasarjana, Universitas Riau Kepulauan, \\ Jl. Pahlawan No. 99 Batu Aji, Batam 29425 \\ email: sarisucahyo@yahoo.com \\ ${ }^{2}$ Fakultas Ekonomi, Universitas Riau Kepulauan, \\ Jl. Pahlawan No. 99 Batu Aji, Batam 29425 \\ email: mutiaseptiani14@yahoo.com
}

\begin{abstract}
Abstrak
Kinerja pegawai merupakan salah satu hal yang sangat menarik untuk diteliti, karena kinerja pegawai sangat menentukan kinerja institusi. Tujuan penelitian ini untuk menganalisis pengaruh kepribadian terhadap kinerja pegawai, orientasi kerja terhadap kinerja pegawai, penempatan terhadap kinerja pegawai, dan kepribadian, orientasi kerja, serta penempatan terhadap kinerja pegawai. Penelitian ini menggunakan metode kuantitatif. Populasi penelitian ini adalah 50 pegawai PT. Asuransi Kredit Indonesia Cabang Batam. Sampel penelitian sebanyak 50 pegawai, dengan teknik sampling sensus. Teknik analisis menggunakan regresi linier berganda. Hasil penelitian ini adalah kepribadian berpengaruh tidak signifikan terhadap kinerja pegawai, orientasi kerja berpengaruh signifikan terhadap kinerja pegawai, dan penempatan berpengaruh tidak signifikan terhadap kinerja pegawai, dan kepribadian, orientasi kerja, dan penempatan secara berpengaruh signifikan terhadap kinerja pegawai.
\end{abstract}

Kata Kunci: Kinerja Pegawai, Kepribadian, Orientasi kerja, Penempatan

\begin{abstract}
Employee performance is one of the things that is very interesting to develop, because employee performance is crucial in determining the performance of partnerships. The purpose of this study was to analyze the effect on employee performance, encourage work on employee performance, placement on employee performance, and personality, encourage work, and placement on employee performance. This research uses quantitative methods. The population of this research is 50 employees of PT. Asuransi Kredit Indonesia Cabang Batam. The research sample of 50 employees, with census sampling technique. The analysis technique uses multiple linear regression. The results of this study indicate that there is no significant difference in employee performance, work planning is significant on employee performance, and placement is not significant on employee performance, and competence, encouraging work, and significant placement on employee performance.
\end{abstract}

Keywords: Employee Performance, Personality, Work Orientation, Placement

\section{PENDAHULUAN}

Sumber daya manusia merupakan salah satu faktor penting dalam organisasi. Oleh karena itu diperlukan manajemen sumber daya manusia yang baik untuk mendukung tercapainya tujuan organisasi, Ratnasari (2012). Manajemen sumber daya manusia merupakan suatu ilmu dan seni untuk mengatur maupun mengarahkan sumber daya manusia untuk mencapai tujuan organisasi secara efektif dan efisien. Efektif berarti dapat mencapai tujuan sesuai dengan perencanaan, dan efisien berarti tugas yang ada dilakukan dengan benar, terorganisir, 
dan sesuai dengan target waktu yang sudah ditetapkan (Montolalu, 2016).

Peranan sumber daya manusia sangat penting dalam suatu perusahaan, sumber daya manusia merupakan salah satu faktor yang ikut terlibat secara langsung dalam menjalankan kegiatan perusahaan dan berperan penting dalam meningkatkan produktivitas perusahaan dalam mencapai tujuan yang telah ditetapkan, Ratnasari (2015). Hal ini sangat berkaitan erat dengan pencapaian kinerja yang tinggi, oleh karena itu perlu dilandaskan pada beberapa pendekatan, salah satunya adalah pendekatan psikologis dan organisasi.

Pendekatan psikologis dan organisasi terhadap kinerja ini diantaranya adalah pendekatan terhadap kepribadian dan kecerdasan emosional dari Sumber Daya Manusia yang ada di dalam perusahaan, Ratnasari (2017).

Setiap instansi dalam melakukan aktivitasnya memiliki tujuan yang harus dicapai. Untuk mencapai atau mewujudkan tujuan tersebut setiap instansi harus pandai dalam memilih strategi terutama adalah perencanaan sumber daya manusia yang pada intinya adalah terfokus pada langkahlangkah tertentu yang diambil oleh manajemen. Atas tersedianya tenaga kerja yang tetap untuk menempati jabatan serta waktu yang tepat dalam rangka pencapaian tujuan dan berbagai sasaran yang ditetapkan. Organisasi terpenting adalah sumber daya manusia, yaitu orang-orang yang memberikan tenaga, bakat maupun organisasi pemerintah tidak terlepas dari kinerja individu.

Memasuki era globalisasi, kebutuhan mutlak akan sumber daya manusia yang tangguh tidak dapat dipungkiri dalam menghadapi era baru ini, organsasi atau perusahaan akan memenuhi suatu bentuk persaingan yang semakin kompleks dengan variasi, intensitas dan cakupan yang mungkin belum pernah dialami sebelumnya, sehingga organisasi membutuhkan orangorang yang tangguh, yang sangup beradaptasi dengan cepat untuk setiap perubahan yang terjadi, yang sanggup bekerja dengan cara-cara baru melalui kecakapan dan tugastugasnya, Yani (2012).

Kinerja individu sebagai perilaku atau tindakan yang berhubungan dengan tujuan perusahaan. Dalam hubungannya dengan pencapaian kinerja yang tinggi, perlu dilandaskan pada beberapa pendekatan, salah satunya adalah pendekatan psikologis dan organisasi. Pendekatan psikologis dan organisasi terhadap kinerja ini diantaranya adalah pendekatan terhadap kepribadian dan kecerdasan emosional dari Sumber Daya Manusia yang ada di dalam perusahaan.

Setiap pegawai yang tergabung dalam suatu organisasi memiliki orientasi kerja masing-masing dan kemungkinan besar pegawai satu dengan lainnya mempunyai orientasi kerja yang berbeda pula, dan apabila orientasi yang dipersepsikannya ini dapat tercapai maka pegawai akan merasakan kepuasan kerja dan bekerja dengan maksimal, Ratnasari dan Sutjahjo (2019).

Menurut Sedarmayanti (2017) orientasi adalah aktivitas yang melibatkan pengenalan karyawan baru kepada organisasi dan unit kerja mereka. Orientasi berarti penyediaan informasi bagi pegawai baru, yaitu 
informasi yang mereka perlukan untuk melaksanakan pekerjaan secara memuaskan.

Untuk mencapai tujuan organisasi secara efektif tentunya diperlukan sumber daya manusia yang berkualitas dan sesuai dengan bidangnya.

Pada saat ini, perusahaan dalam meningkatkan produktivitasnya melakukan suatu bentuk kegiatan yaitu penempatan tenaga kerja atau pegawai yang memiliki tingkat kompeten yang berbeda-beda.

Perbedaan kemampuan ini ditentukan berdasarkan hasil recruitment dan qualification perusahaan. Untuk promosi jabatan itu sendiri ditentukan berdasarkan penampatan kerja itu sendiri. Persaingan dalam duni kerja yang semakin meningkat memacu instansi untuk terus meningkatkan kinerja pegawai agar dapat bekerja dengan baik dan bisa bermanfaat baik untuk perusahaan maupun masyarakat.

Penempatan kerja merupakan salah satu faktor penting yang tidak boleh diabaikan dalam mencapai tujuan instansi atau lembaga. Dewasa ini kebanyakan Organisasi melakukan pengadaan (recruitment) karyawan melalui sistem kedekatan (nepotisme) dan juga melalui sistem sogokan (kolusi). Artinya pihak perusahaan tidak memperhatikan betul latar belakang dari tingkat pendidikan, pengalaman, kesehatan fisik dan mental, dan usia dari calon pegawai itu sendiri. Jika institusi menempatkan karyawan pada tempat yang bukan keahliannya maka kinerja pegawai tidak maksimal sehingga tujuan institusi tidak efektif dan efisien.

\section{HIPOTESIS PENELITIAN}

H1 : Kepribadian berpengaruh terhadap kinerja pegawai.

$\mathrm{H} 2$ : Orientasi kerja berpengaruh terhadap kinerja pegawai.

H3 : Penempatan pegawai berpengaruh terhadap kinerja pegawai.

H4 : Kepribadian, Orientasi kerja dan Penempatan pegawai berpengaruh terhadap kinerja pegawai.

\section{METODE PENELITIAN}

Menurut Sugiyono

mendefinisikan populasi merupakan totalitas dari semua objek atau individu yang memiliki karakteristik tertentu, jelas, lengkap yang akan diteliti.

Objek atau nilai yang akan diteliti dalam populasi disebut unit analisis atau elemen populasi. Adapun populasi penelitian ini adalah seluruh pegawai di PT. Asuransi Kredit Indonesia (Persero) Cabang Batam yang berjumlah 50 orang.

Penelitian ini menggunakan seluruh anggota populasinya total sampling atau sensus. Penggunaan metode ini berlaku jika anggota populasi relative kecil (mudah dijangkau). Dalam penelitian ini, karena jumlah populasi relative kecil dan relative mudah dijangkau, maka digunakan metode total sampling. Dengan metode pengambilan sampel ini diharapkan hasilnya dapat cenderung lebih mendekati nilai sesungguhnya dan diharapkan dapat memperkecil pula terjadinya kesalahan atau penyimpangan terhadap nilai populasi.

Data adalah suatu istilah majemuk yang berarti fakta atau bagian dari fakta yang mengandung arti yang dihubungkan dengan kenyataan, 
simbol-simbol, gambar-gambar, angka-angka, huruf-huruf, atau simbol-simbol yang menunjukkan suatu ide, objek, kondisi atau situasi dan lain-lain (Sunyoto, 2012).

Data yang digunakan dalam penelitian ini meliputi: (1) Data Primer, Data primer merupakan data yang diperoleh secara langsung dari sumber asli (tanpa melalui perantara). Data primer yang ada dalam penelitian ini merupakan data kuesioner yang diperoleh langsung dari pengisian kuesioner oleh pegawai PT. Asuransi Kredit Indonesia (Persero) Cabang Batam. (2) Data Sekunder, Data sekunder adalah data penelitian yang diperoleh secara tidak langsung melalui media perantara (diperoleh dan dicatat oleh pihak lain). Data sekunder dalam penelitian ini adalah data tentang perusahaan meliputi: Gambaran umum perusahaan, struktur organisasi, dan informasi lainnya.

Pada penelitian ini data yang akan dikumpulkan berupa data primer dan data sekunder, maka peneliti akan menggunakan alat pengumpulan data berupa: (a) Kuesioner merupakan teknik pengumpulan data yang dilakukan dengan cara memberikan seperangkat pertanyaan yang berstruktur atau pernyataan secara tertulis kepada responden yang berhubungan dengan penelitian, guna mendapatkan data untuk memecahkan masalah yang diteliti. (b) Observasi merupakan metode pengumpulan data yang dilakukan dengan mendatangi objek penelitian secara langsung, yaitu pada PT. Asuransi Kredit Indonesia (Persero) Cabang Batam. (c) Metode Dokumentasi atau Studi Pustaka. Metode Dokumentasi atau Studi Pustaka adalah suatu cara yang digunakan untuk mencari data mengenai hal-hal variabel berupa catatan, transkip, buku, surat, majalah, agenda dan sebagainya. Metode ini merupakan metode bantu yang digunakan untuk memperoleh data-data menyangkut informasi. Metode yang digunakan merupakan metode pengumpulan data mengenai suatu hal yang pernah terjadi dan didokumentasikan. (d) Metode Wawancara atau Interview. Wawancara atau interview adalah serangkaian wawancara yang dimaksudkan untuk melengkapi kuesioner atau jawaban yang kurang terarah, sehingga dari wawancara ini diharapkan dapat diperoleh keterangan lebih lanjut dari pihak yang bersangkutan.

\section{HASIL DAN PEMBAHASAN} Tabel 1 Uji Validitas

\begin{tabular}{|c|c|c|c|c|c|}
\hline Variabel & Item & r Hitung & r Tabel & Sig & Keterangan \\
\hline \multirow{4}{*}{$\begin{array}{c}\text { Kepribadian } \\
\text { (X1) }\end{array}$} & $\mathrm{X} 1.1$ & 0,441 & 0,2787 & 0.001 & Valid \\
\cline { 2 - 6 } & $\mathrm{X} 1.2$ & 0,537 & 0,2787 & 0.000 & Valid \\
\cline { 2 - 6 } & $\mathrm{X} 1.3$ & 0,617 & 0,2787 & 0.000 & Valid \\
\cline { 2 - 6 } & $\mathrm{X} 1.4$ & 0,646 & 0,2787 & 0.000 & Valid \\
\cline { 2 - 6 } & $\mathrm{X} 1.5$ & 0,441 & 0,2787 & 0.001 & Valid \\
\hline \multirow{4}{*}{$\begin{array}{c}\text { Orientasi } \\
\text { Kerja (X2) }\end{array}$} & $\mathrm{X} 2.1$ & 0,609 & 0,2787 & 0.000 & Valid \\
\cline { 2 - 6 } & $\mathrm{X} 2.2$ & 0,353 & 0,2787 & 0.000 & Valid \\
\cline { 2 - 6 } & $\mathrm{X} 2.3$ & 0,666 & 0,2787 & 0.000 & Valid \\
\cline { 2 - 6 } & $\mathrm{X} 2.4$ & 0,476 & 0,2787 & 0.000 & Valid \\
\cline { 2 - 6 } & $\mathrm{X} 2.5$ & 0,589 & 0,2787 & 0.000 & Valid \\
\hline \multirow{4}{*}{$\begin{array}{c}\text { Penempatan } \\
\text { Pegawai (X3) }\end{array}$} & $\mathrm{X} 3.1$ & 0,433 & 0,2787 & 0.002 & Valid \\
\cline { 2 - 6 } & $\mathrm{X} 3.2$ & 0,434 & 0,2787 & 0.002 & Valid \\
\cline { 2 - 6 } & $\mathrm{X} 3.3$ & 0,554 & 0,2787 & 0.000 & Valid \\
\cline { 2 - 6 } & $\mathrm{X} 3.4$ & 0,561 & 0,2787 & 0.004 & Valid \\
\hline \multirow{4}{*}{\begin{tabular}{|l} 
Kinerja \\
Pegawai (Y)
\end{tabular}} & 0,400 & 0,2787 & 0.000 & Valid \\
\cline { 2 - 6 } & $\mathrm{Y} .1$ & 0,956 & 0,2787 & 0.000 & Valid \\
\cline { 2 - 6 } & $\mathrm{Y} .2$ & 0,528 & 0,2787 & 0.000 & Valid \\
\cline { 2 - 6 } & $\mathrm{Y} .3$ & 0,500 & 0,2787 & 0.000 & Valid \\
\cline { 2 - 6 } & $\mathrm{Y} .4$ & 0,846 & 0,2787 & 0,001 & Valid \\
\hline & $\mathrm{Y} .5$ & 0,868 & 0,2787 & 0.000 & Valid \\
\hline
\end{tabular}

Sumber: Hasil Penelitian, 2018

Hasil uji validitas menunjukkan bahwa semua butir pernyataan mempunyai nilai $r$ hitung $>\mathrm{r}$ tabel, dengan taraf signifikan $\alpha=0,05$ dan nilai $r$ tabel nya sebesar 0.2787 dapat disimpulkan bahwa semua pernyataan pada variabel $\mathrm{X} 1, \mathrm{X} 2$, dan X3 dinyatakan valid. 
Tabel 2 Hasil Uji Reliabilitas

\begin{tabular}{|c|c|c|c|c|}
\hline Variabel & $\begin{array}{l}\text { Alpha } \\
\text { Croulbarh }\end{array}$ & $\begin{array}{l}\text { Noff } \\
\text { Item }\end{array}$ & rTabel & Keterangan \\
\hline Kepribadilian (XI) & 0,530 & $\xi$ & 0,2787 & Reliabel \\
\hline On'entasi Kejia (X2) & 0,41 & 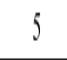 & 0,2787 & Reliabel \\
\hline Penempatan Pegawai (X3) & 0,600 & s & 0,2787 & Reliabel \\
\hline 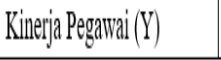 & 0,592 & 5 & 0,2787 & Rellabel \\
\hline
\end{tabular}

Sumber: Hasil penelitian, 2018

Berdasarkan Tabel 2 dapat dilihat bahwa R Alpha dari masing - masing variabel $\mathrm{X} 1, \mathrm{X} 2, \mathrm{X} 3$ dan $\mathrm{Y}$ lebih besar dari 0,2787. Dengan demikian dapat disimpulkan bahwa data yang diuji tersebut dinyatakan reliabel.

Tabel 3 Hasil Uji Normalitas

One-Sample Kolmogorov-Smirnov Test Unstandardized

\begin{tabular}{llr} 
& & \multicolumn{1}{c}{ Residual } \\
\hline $\mathrm{N}$ & & 50 \\
\hline Normal Parameters & Mean & .0000000 \\
\cline { 2 - 3 } & Std. Deviation & .83659450 \\
\hline Most Extreme Differences & Absolute & .165 \\
\cline { 2 - 3 } & Positive & .101 \\
\cline { 2 - 3 } & Negative & -.165 \\
\hline Test Statistic & .165 \\
\hline Asymp. Sig. (2-tailed) & $.202^{c}$ \\
\hline a. Test distribution is Normal. & \\
b. Calculated from data. & \\
c. Lilliefors Significance Correction. &
\end{tabular}

Sumber: Hasil Penelitian, 2018

Berdasarkan hasil uji Kolmogorov-smirnov, diketahui nilai Asymp. Sig. (2-tailed) sebesar 0,202 $>0,05$ (alpha) sehingga dapat disimpulkan bahwa data mempunyai sebaran yang normal.

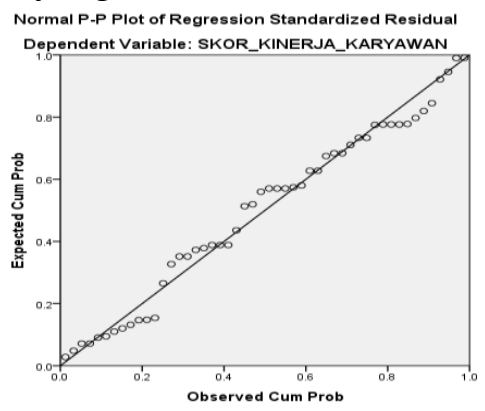

Gambar 1 Hasil Uji Normalitas

Sumber: Hasil Penelitian, 2018
Gambar 1 memperlihatkan ketentuan bahwa titik-titik data menyebar disekitar garis diagonal dan mengikuti arah garis diagonal maka dapat dikatakan data memenuhi asumsi normalitas.

Tabel 4 Uji Multikolonieritas

\begin{tabular}{|l|r|r|}
\hline \multirow{2}{*}{ Model } & \multicolumn{2}{c|}{ Collinearity Statistics } \\
\cline { 2 - 4 } & \multicolumn{1}{|c|}{ Tolerance } & \multicolumn{1}{c|}{ VIF } \\
\hline (Constant) & & \\
KEPRIBADIAN &, 947 & 2,760 \\
\hline ORIENTASI KERJA &, 823 & 2,753 \\
\hline PENEMPATAN PEGAWAI &, 786 & 4,174 \\
\hline
\end{tabular}

Sumber: Hasil Penelitian, 2018

Tabel 4 menunjukkan bahwa nilai VIF untuk variabel $\mathrm{X} 1, \mathrm{X} 2$, dan X3 masing-masing sebesar 2,760; 2,753; dan 4,174 sehingga dapat disimpulkan bahwa dalam model regresi tidak terdapat gejala multikolinearitas antar variabel bebas karena nilai VIF nya lebih kecil dari 10 yang berarti bahwa semua variabel tersebut dapat digunakan sebagai variabel yang saling independen.

\section{Tabel 5 Uji Heteroskedastisitas}

\begin{tabular}{|c|c|c|}
\hline Model & $\mathrm{T}$ & Sig. \\
\hline (Constant) & 2,073 &, 044 \\
\hline KEPRIBADIAN &,- 580 &, 565 \\
\hline ORIENTASI KERJA &,- 568 &, 572 \\
\hline PENEMPATAN PEGAWAI &, 302 &, 764 \\
\hline
\end{tabular}

Sumber: Hasil Penelitian, 2018

Hasil pengujian Park Gleyser melihat nilai probabilitas dengan signifikansi > nilai alpha $(0,05)$ maka model tidak mengalami heteroskedastisitas (Wibowo, 2012). 
Pada Tabel 5 diketahui bahwa nilai probabilitas atau signifikansi dari masing-masing variabel 0,565 ; 0,572; dan 0,764 lebih besar dari nilai alpha $(0,05)$ maka dapat disimpulkan bahwa dalam model regresi tidak terdapat gejala heteroskedastisitas.

\section{PENGUJIAN HIPOTESIS}

Tabel 6 Hasil Uji t (Parsial)

\begin{tabular}{|c|c|c|c|c|c|}
\hline \multirow[t]{2}{*}{ Modelel } & \multicolumn{2}{|c|}{$\begin{array}{l}\text { Unstancardicized } \\
\text { Coefficents }\end{array}$} & \multirow{2}{*}{\begin{tabular}{|c|}
$\begin{array}{c}\text { Standardized } \\
\text { Coefficients }\end{array}$ \\
Beta \\
\end{tabular}} & \multirow[t]{2}{*}{$T$} & \multirow[t]{2}{*}{ Sig. } \\
\hline & $B$ & Stot. Eror & & & \\
\hline (Constant) & 6,077 & 2,322 & & 2,617 &, 012 \\
\hline KEPR|BADIAN &, 188 &, 161 & 190 & 1,68 & 249 \\
\hline ORENTASS KERJA & .888 &, 158 & 600 & 3,692 &, 001 \\
\hline PENENPATAN PEGAWAI & .661 & 180 & .007 & 3,05 & 971 \\
\hline
\end{tabular}

Sumber: Hasil Penelitian, 2018

Tabel 6 menunjukkan bahwa variabel kepribadian (X1) nilai $\mathrm{t}$ hitung $1,168<\mathrm{t}$ tabel 2,01290 dan nilai signifikan $0,249>0,05$ sehingga keputusan yang diambil adalah $\mathrm{H}_{\mathrm{o}}$ diterima dan $\mathrm{H}_{\mathrm{a}}$ ditolak. Hal ini berarti bahwa Kepribadian berpengaruh tidak signifikan terhadap kinerja pegawai. Hasil penelitian mendukung hasil penelitian Dewi (2016), Isvandiari dan Susilo (2014), Montolalu (2016), Rahayu (2016), dan Syafitri (2016).

Variabel orientasi kerja (X2) menunjukkan nilai $\mathrm{t}$ hitung 3,692 >t tabel 2,01290 dan nilai signifikan $0,001<0,05$ sehingga keputusan yang diambil adalah $\mathrm{H}_{\mathrm{o}}$ ditolak dan $\mathrm{H}_{\mathrm{a}}$ diterima. Hal ini berarti bahwa Orientasi kerja berpengaruh signifikan terhadap kinerja pegawai. Hasil penelitian ini mendukung hasil penelitian Hartanto (2010), Maabuat (2016), dan Montalalu (2016).

Variabel penempatan pegawai (X3) nilai t hitung $0,037<\mathrm{t}$ tabel 2,01290 dan nilai signifikan $0,971>$ 0,05 sehingga keputusan yang diambil adalah $\mathrm{H}_{\mathrm{o}}$ diterima dan $\mathrm{H}_{\mathrm{a}}$ ditolak. Hal ini berarti bahwa Penempatan pegawai berpengaruh tidak signifikan terhadap Kinerja pegawai. Hasil penelitian ini mendukung hasil penelitian Atkhan (2013), Efendy (2017), Montolalu (2016), Muaja (2017).

Tabel 7 Hasil Uji F (Simultan)

\begin{tabular}{l|r|r|r|r|r|}
\hline \multicolumn{1}{|c|}{ ANOVA $^{\mathrm{a}}$} \\
\hline Model & Sum of Squares & Df & $\begin{array}{c}\text { Mean } \\
\text { Square }\end{array}$ & F & Sig. \\
\hline Regression & 107,192 & 3 & 35,731 & 19,376 &, $000^{\mathrm{b}}$ \\
Residual & 84,828 & 46 & 1,844 & & \\
Total & 192,020 & 49 & & & \\
\hline a. Dependent Variable: KINERJA PEGAWAI \\
b. Predictors: (Constant), KEPRIBADIAN, ORIENTASI KERJA, PENEMPATAN PEGAWAI
\end{tabular}

Sumber: Hasil Penelitian, 2018

Hasil uji $\mathrm{F}$ memperlihatkan nilai $\mathrm{F}$ sebesar 19,376 (F hitung) > 2,81 (F tabel) dan nilai probabilitas signifikansi sebesar $0,000<0,05$ sehingga keputusan yang diambil adalah $\mathrm{H}_{\mathrm{o}}$ ditolak dan $\mathrm{H}_{\mathrm{a}}$ diterima. Hasil ini menunjukkan bahwa variabel Kepribadian (X1), Orientasi kerja (X2), dan Penempatan pegawai (X3) mampu menjelaskan keragaman dari variabel terikat secara bersamasama terhadap variabel Kinerja pegawai (Y). 
Tabel 8 Uji Koefisien Determinasi (R2)

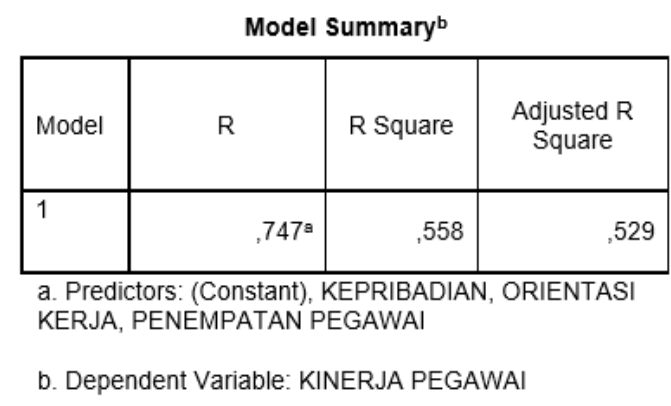

Sumber: Hasil Penelitian, 2018

Hasil Uji Koefisien Determinasi memperlihatkan nilai $\mathrm{R}$ Square sebesar 0,558 artinya korelasi antara variabel kepribadian (X1), orientasi kerja (X2), dan penempatan pegawai (X3) terhadap variabel kinerja pegawai (Y) dalam model regresi sebesar $55,8 \%$. Hasil pengujian nilai Adjusted $R$ Square sebesar 0,558 atau $55,8 \%$ dari kinerja pegawai dapat dipengaruhi oleh variabel kepribadian (X1), orientasi kerja (X2), dan penempatan pegawai (X3). Sisanya $44,2 \%$ kinerja pegawai dipengaruhi oleh variabel-variabel lain yang tidak dijelaskan dalam penelitian ini.

\section{SIMPULAN}

Berdasarkan hasil penelitian dan pembahasan yang telah dilakukan, maka dapat disimpulkan bahwa: (1) Pengujian hipotesis untuk variabel kepribadian menunjukkan hasil $\mathrm{t}$ hitung $1,168<\mathrm{t}$ tabel 2,01290 dan nilai signifikan $0,249>0,05$ sehingga keputusan yang diambil adalah $\mathrm{H}_{\mathrm{o}}$ ditolak dan $\mathrm{H}_{\mathrm{a}}$ diterima. Hal ini berarti bahwa kepribadian tidak berpengaruh secara positif dan signifikan terhadap kinerja pegawai PT. Asuransi Kredit Indonesia (Persero) Cabang Batam. (2) Pengujian hipotesis untuk variabel orientasi kerja menunjukkan hasil $\mathrm{t}$ hitung 3,692 > t tabel 2,01290 dan nilai signifikan $0,001<0,05$ sehingga keputusan yang diambil adalah $\mathrm{H}_{\mathrm{o}}$ ditolak dan $\mathrm{H}_{\mathrm{a}}$ diterima. Hal ini berarti bahwa orientasi kerja berpengaruh secara positif dan signifikan terhadap kinerja pegawai PT. Asuransi Kredit (Persero) Indonesia Cabang Batam.

Pengujian hipotesis untuk variabel penempatan pegawai menunjukkan hasil $t$ hitung $0,037<\mathrm{t}$ tabel 2.01290 dan nilai signifikan $0,971>$ 0,05 sehingga keputusan yang diambil adalah $\mathrm{H}_{\mathrm{o}}$ ditolak dan $\mathrm{H}_{\mathrm{a}}$ diterima. Hal ini berarti bahwa penempatan berpengaruh tidak signifikan terhadap kinerja pegawai PT. Asuransi Kredit Indonesia (Persero) Cabang Batam. (4) Hasil uji $\mathrm{F}$ memperlihatkan nilai $\mathrm{F}$ sebesar 19,376 (F hitung) > 0.2787 (F tabel), diperkuat dengan nilai probabilitas signifikansi sebesar $0,000<0,05$ sehingga keputusan yang diambil adalah $\mathrm{H}_{\mathrm{o}}$ ditolak dan $\mathrm{H}_{\mathrm{a}}$ diterima. Hasil ini menunjukkan bahwa variabel kepribadian, orientasi kerja, dan penempatan pegawai secara bersama-sama berpengaruh signifikan terhadap kinerja pegawai PT. Asuransi Kredit Indonesia (Persero) Cabang Batam.

\section{DAFTAR PUSTAKA}

A, Atkhan. 2013. Pengaruh Penempatan Kerja Terhadap Kinerja Pegawai Pada Dinas Perkebunan Provinsi Kalimantan Timur. eJournal Administrative Reform. 1 (1): 257 - 271.

Dewi, Lusyana. 2016. Pengaruh Kepribadian dan Kecerdasan Emosional Terhadap Kinerja Karyawan Studi Kasus Pada Stasiun TV di Lampung. Skripsi. 
Fakultas Ekonomi dan Bisnis Universitas Lampung.

Efendy, Evy. S. 2017. Pengaruh Penempatan Kerja Terhadap Kinerja Pegawai Pada Kantor Kejaksaan Negeri Kendari. Skripsi. Program Studi Manajemen. Fakultas Ekonomi dan Bisnis. Universitas Halu Eleo Kendari.

Hartanto, Intan. A. 2010. Pengaruh Orientasi Pembelajaran Terhadap Kinerja Karyawan dengan Kepuasan Kerja sebagai Variabel Pemediasi Pada Karyawan Kantor Sekretariat Daerah Kabupaten Sragen. Skripsi. Program Studi Manajemen. Fakultas Ekonomi. Universitas Sebelas Maret Surakarta.

Isvandiari, Any dan Susilo, Amin. 2014. Pengaruh Kepribadian dan Disiplin Kerja Terhadap Kinerja Karyawan Studi Kasus Dinas Luar Asuransi Jiwa Bersama Bumi Putera 1912 Cabang Dieng Malang. Jurnal JIBEKA. Volume 8 No 2 Agustus 2014 : $1-6$.

Maabuat, S. Edward. 2016. Pengaruh Kepemimpinan, Orientasi Kerja dan Budaya Organisasi Terhadap Kinerja Pegawai Studi Kasus Dispenda Sulut UPTD Tondano. Jurnal Berkala Ilmiah Efesiensi. Volume 16 No. 01.

Montolalu, Ricky. 2016. Pengaruh Kepribadian, Orientasi Kerja dan Penempatan Pegawai Terhadap Kinerja Pegawai: Studi Kasus Dinas Kebudayaan dan Pariwisata Provinsi Sulawesi Utara. Jurnal EMBA. Vol.4 No.1 Maret 2016, Hal. 1318-1329.

Muaja, KO. 2017. Pengaruh Penempatan Kerja dan Pengalaman Kerja Terhadap Kinerja Karyawan Studi Kasus
PT. Bank Sulutgo Kantor Cabang Utama Manado. Jurnal EMBA. Vol.5 No.2 Juni 2017. Hal. 2211 2220.

Rahayu, Sri. Pengaruh Kepribadian dan Pemberdayaan Terhadap Kinerja melalui Organizational Citizendship Behavior dengan Modal Sosial sebagai variabel Moderating. Prosiding Seminar Nasional Multi Disiplin Ilmu \& Call Unisbank (SENDI_U). ISBN: 978-979-3649-81-8.

Ratnasari, Sri Langgeng. 2012. Manajemen Sumber Daya Manusia. Surabaya: Penerbit Semesta Anugrah.

Ratnasari, Sri Langgeng. 2017. Perencanaan Sumber Daya Manuasia. Surabaya: Unggul Pangestu Nirmana.

Ratnasari, Sri Langgeng., and Sutjahjo, Gandhi. 2019. How to Improve Performance? International Journal of Recent Technology and Engineering. Vol.8., Issue 3S2. Pp. 625-628.

Sedarmayanti. 2017. Manajemen Sumber Daya Manusia. Bandung: Refika Aditama.

Sugiyono. 2017. Metode Penenelitian Kuantitatif Kualitatif Dan R\&D. Bandung: CV. Alfabeta.

Sunyoto, Danang. 2012, Teori Kuesioner, Dan Analisis Data Sumber Daya Manusia (praktek penelitian). Cetakan Pertama. Yogyakarta: CAPS.

Syafitri, Agustine. 2016. Pengaruh Kepribadian dan Kemampuan Terhadap Motivasi dan Kinerja Karyawan. Jurnal Ilmu dan Riset Manajemen. Volume 5. Nomor 9.

Yani, M. 2012, Manajemen Sumber Daya Manusia, Jakarta: Mitra Wacana Media. 